\title{
Comparative study on health care utilization and hospital outcomes of severe acute exacerbation of chronic obstructive pulmonary disease managed by pulmonologists vs internists
}

\author{
This article was published in the following Dove Press journal: \\ International Journal of COPD \\ 13 April 2015 \\ Number of times this article has been viewed
}

\section{Chaicharn Pothirat \\ Chalerm Liwsrisakun Chaiwat Bumroongkit \\ Athavudh Deesomchok \\ Theerakorn Theerakittikul \\ Atikun Limsukon \\ Division of Pulmonary, Critical Care and Allergy, Department of Internal Medicine, Faculty of Medicine, Chiang Mai University, Chiang Mai, Thailand}

Correspondence: Chaicharn Pothirat Division of Pulmonary, Critical Care and Allergy, Department of Internal Medicine, Faculty of Medicine, Chiang Mai University, I 10 Inthavaroros Road, Sriphum, Maung Chiang Mai District, Chiang Mai 50200, Thailand

Tel +6653946228

Fax+6653895117

Email cpothira@med.cmu.ac.th; chaicharn.p@cmu.ac.th
Background: Care for many chronic health conditions is delivered by both specialists and generalists. Differences in patients' quality of care and management between generalists and specialists have been well documented for asthma, whereas a few studies for COPD reported no differences.

Objective: The objective of this study is to compare consistency with Global initiative for chronic Obstructive Lung Disease guidelines, as well as rate, health care utilization, and hospital outcomes of severe acute exacerbation (AE) of COPD patients managed by pulmonologists and internists.

Materials and methods: This is a 12-month prospective, comparative observational study among 208 COPD patients who were regularly managed by pulmonologists (Group A) and internists (Group B). Clinical data, health care utilization, and hospital outcomes of the two groups were statistically compared.

Results: Out of 208 enrolled patients, 137 (Group A) and 71 (Group B) were managed by pulmonologists and internists, respectively. Pharmacological treatment corresponding to disease severity stages between the two groups was not statistically different. Group A received care consistent with guidelines in terms of annual influenza vaccination $(31.4 \%$ vs $9.9 \%, P<0.001)$ and pulmonary rehabilitation $(24.1 \%$ vs $0 \%, P<0.001)$ greater than Group B. Group A had reduced rates $(12.4 \%$ vs $23.9 \%, P=0.033)$ and numbers of severe $\mathrm{AE}(0.20 \pm 0.63$ person-years vs $0.41 \pm 0.80$ person-years, $P=0.029)$. Among patients with severe $\mathrm{AE}$ requiring mechanical ventilation, Group A had reduced mechanical ventilator duration (1.5 [1-7] days vs 5 [3-29] days, $P=0.005)$, hospital length of stay (3.5 [1-20] days vs 16 [6-29] days, $P=0.012$ ), and total hospital cost (\$863 [247-2,496] vs $\$ 2,095$ [763-6,792], $P=0.049)$ as compared with Group B.

Conclusion: This study demonstrated that pulmonologists followed national COPD guidelines more closely than internists. The rates and frequencies of severe AE were significantly lower in patients managed by pulmonologists, and length of hospital stay and cost were significantly lower among the patients with severe $\mathrm{AE}$ who required mechanical ventilation.

Keywords: chronic obstructive pulmonary disease, guidelines, specialization, management

\section{Introduction}

COPD, a chronic inflammatory airway condition associated with episodes of acute deterioration termed exacerbations, ${ }^{1}$ is a major cause of chronic morbidity and mortality worldwide. ${ }^{2}$ The natural history of COPD is interrupted by episodes of worsening symptoms and signs of accelerating lung function decline ${ }^{3,4}$ leading to decreases in health-related quality of life, ${ }^{5,6}$ increased mortality, ${ }^{7,8}$ and health 
care costs. ${ }^{9,10}$ The Global initiative for chronic Obstructive Lung Disease (GOLD) is a collaborative project of the US National Heart, Lung, and Blood Institute and the World Health Organization. Its goals are to increase awareness of COPD and decrease morbidity and mortality from this disease by improving prevention and management of COPD. ${ }^{11}$ Care for many chronic health conditions including COPD is delivered by both specialists and generalists. Differences in patients' quality of care and management between generalists and specialists have been well documented for asthma, ${ }^{12-14}$ whereas a few studies for COPD reported no differences. ${ }^{15-17}$ In Thailand, health care utilization and hospital outcomes of COPD patients managed by pulmonologists and internists have never been studied. We hypothesized that patients managed by pulmonologists will be treated according more closely to GOLD guidelines, and will have less severe exacerbations, more favorable health care utilization, and better hospital outcomes.

\section{Materials and methods Study design}

This is a prospective, comparative observational study among COPD patients who were regularly managed by pulmonologists and internists at the two outpatient clinics, a pulmonologist clinic (Group A) and a general internal medicine clinic (Group B) of Department of Internal Medicine, Faculty of Medicine, Chiang Mai University Hospital, Chiang Mai, Thailand, from August 1, 2009 to July 31, 2010. Group A COPD patients were selected from out- or inpatient services of the department for further investigations and/or management judged by internists. Group B COPD patients were referred from community or provincial hospitals in the northern part of Thailand attended by general internal medicine rotating internists. Eligible patients were required to meet the criteria for COPD diagnosis as follows: current smokers or ex-smokers with a smoking history $\geq 10$ packyears, onset of breathlessness after 40 years of age, a ratio of post-bronchodilator (BD) forced expiratory volume in the first second $\left(\mathrm{FEV}_{1}\right)$ to forced vital capacity less than 0.7 performed in accordance with guidelines of the American Thoracic Society and the European Respiratory Society, ${ }^{18}$ and a normal or abnormal chest radiograph compatible with the disease. All eligible COPD patients received confirmation diagnosis by a pulmonologist at our pulmonary function test laboratory and were regularly managed at either pulmonologist or general internal medicine clinic for at least 12 months prior to enrollment. Patients were excluded if they were diagnosed with asthma at age less than 40 years, visited both a general internal medicine and a pulmonologist clinic, were followed up at the clinics for less than 1 year, visited clinic irregularly or were lost to follow-up at the clinics, or were referred to other hospitals. All eligible patients were advised to come to the emergency department or clinics before routine appointment dates in case they felt deterioration of their respiratory symptoms. Six pulmonologists and two supervised pulmonary fellows provided care for Group A patients; Group B patients were attended by 25 rotating internists (qualified as generalists and in residency training for Thai Board of Internal Medicine). Internists were supervised by rotating general internal medicine staff, and details of pulmonologists and internists are shown in Table 1. During the study period, patients had regular routine follow-up visits at 1-month to 3 -month intervals with their physicians. Data reviewed from physician-maintained records include documentation of symptoms, onset and duration of disease, age of disease onset, tobacco use, $\%$ predicted of post-BD FEV ${ }_{1}$, GOLD staging, comorbidities, use of reliever and controller medications, influenza vaccine prescription, education on self-management plan and instructions for air pollution avoidance, and completion of a course of pulmonary rehabilitation (Suandok exercise training program). ${ }^{19}$ Acute exacerbation (AE) was defined as physician-diagnosed worsening of two or more of the following major symptoms for $\geq 2$ consecutive days dispend, sputum volume, and sputum purulence requiring treatment with systemic corticosteroids and/or antibiotics without new pulmonary infiltration on chest radiographs. ${ }^{1}$ Severe AE was defined as any hospitalization related to COPD. The episodes and possible causes of severe AE were assessed from physician's medical records. Health care resource utilization, hospital length of stay, and costs of care were reviewed using hospital databases. Evaluation of COPD management between the two groups was based on adherence to international GOLD guidelines ${ }^{11}$ using pharmacological, nonpharmacological, and educational parts. The study protocol

Table I Characteristics of pulmonologists and internists involved in this study

\begin{tabular}{|c|c|c|c|}
\hline \multirow[t]{2}{*}{ Variables } & \multirow{2}{*}{$\begin{array}{l}\text { Pulmonologist } \\
\mathrm{N}=8\end{array}$} & \multirow{2}{*}{$\frac{\text { Internists }}{\mathrm{N}=\mathbf{2 5}}$} & \multirow[t]{2}{*}{$P$-value } \\
\hline & & & \\
\hline Age (years) & $40 . I \pm 6.8$ & $28.4 \pm 2.0$ & $<0.001$ \\
\hline Male sex & 7 (87.5) & $12(48.0)$ & 0.049 \\
\hline $\begin{array}{l}\text { Experience in internal } \\
\text { medicine (years) }\end{array}$ & $12.6 \pm 7.2$ & $3.6 \pm 1.4$ & $<0.001$ \\
\hline
\end{tabular}

Notes: Results are expressed as mean \pm standard deviation or $\mathrm{n}(\%)$. Bold values indicate $P$-value reached statistical significance $(<0.05)$. 
was approved by the Ethics Committees of the Faculty of Medicine, Chiang Mai University.

\section{Statistical analysis}

The aim of this study was to compare consistency with international guidelines, between pulmonologists and internists using rate, health care utilization, and hospital outcomes of severe AE of COPD patients managed by pulmonologists and internists. Results for numerical values were expressed as mean \pm standard deviation, and those for categorical data were expressed as absolute frequencies and percentages. Categorical variables were analyzed using Fisher's exact test, while continuous variables were compared using MannWhitney $U$-test. Statistical significance was set at $P<0.05$. All analyses were conducted using the SPSS statistical package, version 16 for Windows.

\section{Results}

Characteristics of the two groups of physicians are shown in Table 1. The mean age and experience in internal medicine of physicians in Group A were higher than those in Group B $(P<0.001)$.

Out of a total of 310 patients diagnosed with COPD, 208 patients (137 in Group A and 71 in Group B) were eligible for the study (Figure 1). The characteristics of patients excluded due to irregular clinical visits were not different from their groups. Characteristics of the two groups of patients are shown in Table 2. Distribution by age and sex was similar in both groups. Body mass index (BMI) in Group B was higher than Group A. Patients in Group A had a longer duration of disease and an earlier age of disease onset. In addition, patients in Group A had more severe impairment of pulmonary
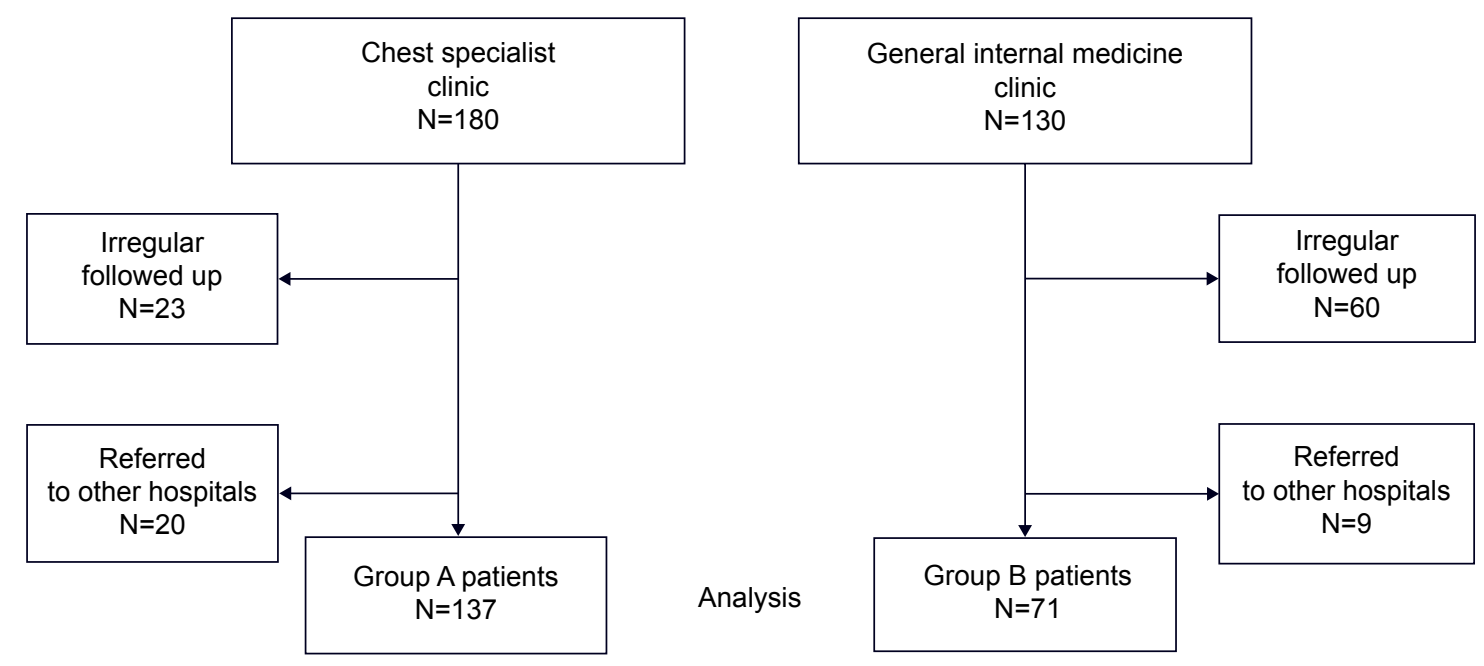

function in terms of mean post-BD FEV 1 and GOLD stages. Evaluation of comorbidities also revealed that diabetes mellitus and dyslipidemia were more often addressed in Group B than Group A. Rates (\%) and frequencies (patient-years) of severe AE were significantly lower in Group A (Table 2).

The study assessed three parts of COPD management: pharmacological management, non-pharmacological management, and education (Table 3). Regarding pharmacological management, the uses of controller medications between the two groups were significantly different. Fixed combinations of short-acting beta-2 agonist plus short-acting anticholinergic in the same device were more frequently prescribed in Group B. In contrary, the use of triple therapy (combined use of inhaled corticosteroid and long-acting beta-2 agonist, with long-acting anticholinergic) was more frequently prescribed in Group A. However, there was no difference in overall optimal pharmacological management based on GOLD stages between the two groups. Documentations on the use of other reliever and controller medications were similar in both groups. For non-pharmacological treatment, Group A received annual influenza vaccination and pulmonary rehabilitation more often than Group B. Overall, assessed non-pharmacological management measures corresponding to GOLD stages were significantly higher in Group A, as well as completed education on self-management plan and instruction for air pollution avoidance (Table 3 ).

Characteristics of severe AE in both groups, 17 from each group, were similar in terms of age, sex, BMI, smoking status, age of disease onset, disease severity, comorbidities, and pharmacological and non-pharmacological managements except that Group A used more triple therapy and had greater knowledge on self-management plan and air pollution

Figure I Flowchart showing participation throughout the study. 
Table 2 Characteristics of COPD patients in Group A and Group B

\begin{tabular}{|c|c|c|c|}
\hline \multirow[t]{2}{*}{ Variables } & \multirow{2}{*}{$\frac{\text { Pulmonologist (Group A) }}{\mathrm{N}=137}$} & \multirow{2}{*}{$\frac{\text { Internists (Group B) }}{\mathrm{N}=\mathbf{7} \text { I }}$} & \multirow[t]{2}{*}{$P$-value } \\
\hline & & & \\
\hline Age (years) & $72.9 \pm 8.6$ & $70.6 \pm 8.8$ & 0.307 \\
\hline Male sex & $77(56.2)$ & $44(62.0)$ & 0.424 \\
\hline Body mass index $\left(\mathrm{kg} / \mathrm{m}^{2}\right)$ & $20.2 \pm 3.7$ & $21.9 \pm 5.2$ & 0.016 \\
\hline Current smoker & $10(7.3)$ & $8(11.3)$ & 0.523 \\
\hline Duration of symptom (years) & $8.8 \pm 6.7$ & $6.3 \pm 5.2$ & 0.031 \\
\hline Duration from diagnosis (years) & $8.1 \pm 6.7$ & $3.4 \pm 4.1$ & $<\mathbf{0 . 0 0 1}$ \\
\hline Age of disease onset (years) & $63.7 \pm 10.1$ & $67.2 \pm 9.6$ & 0.048 \\
\hline$\%$ predicted of post-BD FEV & $47.4 \pm 17.6$ & $61.0 \pm 25.1$ & $<\mathbf{0 . 0 0 1}$ \\
\hline \multicolumn{4}{|l|}{ GOLD staging } \\
\hline I & $8(5.8)$ & $15(2 \mid .1)$ & 0.020 \\
\hline II & $52(38.0)$ & $29(40.8)$ & \\
\hline III & $49(35.8)$ & $21(29.6)$ & \\
\hline IV & $28(20.4)$ & $6(8.5)$ & \\
\hline \multicolumn{4}{|l|}{ Comorbidities } \\
\hline Diabetes mellitus & $10(7.3)$ & $14(19.7)$ & 0.008 \\
\hline Hypertension & $54(39.4)$ & $35(49.3)$ & 0.172 \\
\hline Dyslipidemia & $22(16.1)$ & $21(29.6)$ & 0.022 \\
\hline Chronic kidney disease & $9(6.6)$ & $5(7.0)$ & 0.897 \\
\hline Coronary artery disease & $12(87.3)$ & $9(12.7)$ & 0.374 \\
\hline Malignancy & $8(5.8)$ & $3(4.2)$ & 0.622 \\
\hline \multicolumn{4}{|l|}{ Severe AE } \\
\hline Rate & $17(12.4)$ & 17 (23.9) & 0.033 \\
\hline Number of severe $\mathrm{AE}$ (patient-years) & $0.20 \pm 0.63$ & $0.4 I \pm 0.80$ & 0.029 \\
\hline
\end{tabular}

Notes: Results are expressed as mean \pm standard deviation or $\mathrm{n}(\%)$. Bold values indicate $P$-value reached statistical significance $(<0.05)$.

Abbreviations: $\mathrm{BD}$, bronchodilator; $\mathrm{FEV}_{1}$, forced expiratory volume in the first second; GOLD, Global initiative for chronic Obstructive Lung Disease; AE, acute exacerbation.

avoidance (Table 4). Median time from onset of AE to admission tended to be shorter among Group A patients. Lower respiratory tract infection was more common in Group A, and air pollution exposure was more common in Group B. There was no statistically significant difference in the hospital length of stay and hospital costs between the two groups (Table 5).

No significant difference in hospital death was found; however, the readmission rate with pneumonia in Group B was significantly higher (Table 6).

Severe AE patients requiring mechanical ventilation were further explored (Table 7). Mean mechanical ventilation days, as well as length of stays, were shorter in Group A. In contrast, costs of chest radiography and total costs of hospitalization were significantly higher in Group B. The costs for drugs, laboratory tests, and room with nursing service for treatment tended to be higher in Group B.

\section{Discussion}

The pulmonologists in this study had much more experience in internal medicine than internist. Although the pharmacological management corresponding to the guidelines was not significantly different between the two groups, Group B received a combination of short-acting beta-2 agonist and short-acting anticholinergic in a single device as a controller more often than Group A, and Group A received triple therapy more often than Group B. The different patterns of pharmacological use were likely due to the differences in disease severity stages between the two groups. Group B had a higher proportion of GOLD stage I patients than Group A $(21.1 \%$ vs $5.8 \%$ ); the internists, therefore, would preferentially use a short-acting bronchodilator as a controller. In contrast, Group A had a higher proportion of GOLD stage IV patients than Group B (20.4\% vs 8.5\%); the pulmonologists would preferentially use triple therapy for them. It was possible that patients with severe or unable-to-control disease be referred from internists to pulmonologists for specialized management very early in their treatment cycle. This could be reflected from the findings that patients in Group A had a longer duration of illness and more severe disease as presented by lower FEV ${ }_{1}$ than those in Group B. In contrast, a nonpharmacological management was strikingly different. Rates 
Table 3 Use of COPD medications in Group A and Group B

\begin{tabular}{|c|c|c|c|}
\hline \multirow[t]{2}{*}{ Variables } & \multirow{2}{*}{$\begin{array}{l}\text { Pulmonologist (Group A) } \\
N=137\end{array}$} & \multirow{2}{*}{$\frac{\text { Internists (Group B) }}{\mathbf{N}=\mathbf{7} \text { I }}$} & \multirow[t]{2}{*}{$P$-value } \\
\hline & & & \\
\hline \multicolumn{4}{|l|}{ Pharmacological management } \\
\hline \multicolumn{4}{|l|}{ Reliever } \\
\hline Combined SABA + SAAC & $136(99.3)$ & $71(100)$ & 0.471 \\
\hline \multicolumn{4}{|l|}{ Controller } \\
\hline Combined SABA + SAAC & $5(3.6)$ & $12(16.9)$ & 0.001 \\
\hline LAAC alone & $7(5.1)$ & $\mathrm{I}(\mathrm{I} .4)$ & 0.070 \\
\hline ICS alone & $0(0)$ & $\mathrm{I}(\mathrm{I} .4)$ & 0.452 \\
\hline Combined ICS + LABA & $69(50.4)$ & $48(67.6)$ & 0.337 \\
\hline Triple therapy (ICS + LABA + LAAC) & $56(40.9)$ & $9(12.7)$ & $<0.001$ \\
\hline Methylxanthines & $97(70.8)$ & $45(63.4)$ & 0.275 \\
\hline Optimal pharmacological treatment & $136(99.3)$ & $69(97.2)$ & 0.231 \\
\hline \multicolumn{4}{|l|}{ corresponding to GOLD stages } \\
\hline I 120 & $8(100.0)$ & $15(100.0)$ & \\
\hline II & $52(100.0)$ & $28(96.6)$ & \\
\hline III & $49(100.0)$ & $21(100.0)$ & 0.231 \\
\hline IV & $27(96.4)$ & $5(83.3)$ & \\
\hline \multicolumn{4}{|l|}{ Non-pharmacological management } \\
\hline LTOT & $20(14.6)$ & $9(12.7)$ & 0.704 \\
\hline Influenza vaccination in the past year & $43(31.4)$ & $7(9.9)$ & $<0.001$ \\
\hline Completion of pulmonary rehabilitation & $33(24.1)$ & $0(0.0)$ & $<0.001$ \\
\hline Optimal non-pharmacological management & $42(30.7)$ & $7(9.9)$ & 0.001 \\
\hline \multicolumn{4}{|l|}{ corresponding to GOLD stages } \\
\hline \multicolumn{4}{|l|}{ Education } \\
\hline Self-management plan & $93(67.9)$ & $0(0.0)$ & $<0.001$ \\
\hline Air pollution avoidance & $137(100.0)$ & $12(16.9)$ & $<0.001$ \\
\hline
\end{tabular}

Notes: Results are expressed as $\mathrm{n}(\%)$. Bold values indicate $P$-value reached statistical significance $(<0.05)$.

Abbreviations: SABA, short-acting beta-2 agonist; SAAC, short-acting anticholinergic; LAAC, long-acting anticholinergic; ICS, inhaled corticosteroid; LABA, long-acting beta-2 agonist; GOLD, Global initiative for chronic Obstructive Lung Disease; LTOT, long-term oxygen therapy.

of annual influenza vaccination and pulmonary rehabilitation were significantly greater in Group A. Although care by pulmonologists appeared to be better than that by internists on annual influenza vaccination and pulmonary rehabilitation, there were also opportunities for enhancement with regard to compliance with guidelines for both groups. Despite a national health policy that provides free annual influenza vaccinations, the rates of vaccination were quite low in both groups. Pulmonary rehabilitation was a highly effective and safe intervention to reduce hospital admissions and mortality, and to improve

Table 4 Use of medications in COPD patients with severe acute exacerbation

\begin{tabular}{|c|c|c|c|}
\hline \multirow[t]{2}{*}{ Variables } & \multirow{2}{*}{$\begin{array}{l}\text { Pulmonologist (Group A) } \\
\mathrm{N}=17\end{array}$} & \multirow{2}{*}{$\begin{array}{l}\text { Internists (Group B) } \\
\mathrm{N}=17\end{array}$} & \multirow[t]{2}{*}{$P$-value } \\
\hline & & & \\
\hline \multicolumn{4}{|l|}{ Reliever } \\
\hline Combined SABA + SAAC & $17(100.0)$ & $17(100.0)$ & - \\
\hline \multicolumn{4}{|l|}{ Controller } \\
\hline Combined SABA + SAAC & $0(0.0)$ & $2(11.8)$ & 0.145 \\
\hline LAAC alone & I (5.8) & $0(0.0)$ & 0.310 \\
\hline Combined ICS + LABA & I0 (58.8) & $14(82.4)$ & 0.545 \\
\hline Triple therapy & $6(30.4)$ & I (5.8) & 0.034 \\
\hline Methylxanthines & $15(88.2)$ & $13(76.5)$ & 0.368 \\
\hline \multicolumn{4}{|l|}{ Other managements } \\
\hline LTOT & $6(35.3)$ & $7(4 \mid .2)$ & 0.724 \\
\hline Influenza vaccine in the past year & I (5.9) & $2(11.8)$ & 0.545 \\
\hline Rehabilitation & I (5.9) & $0(0.0)$ & 0.310 \\
\hline
\end{tabular}

Notes: Results are expressed as $n(\%)$. Bold value indicates $P$-value reached statistical significance $(<0.05)$.

Abbreviations: SABA, short-acting beta-2 agonist; SAAC, short-acting anticholinergic; LAAC, long-acting anticholinergic; ICS, inhaled corticosteroid; LABA, long-acting beta-2 agonist; LTOT, long-term oxygen therapy. 
Table 5 Characteristics of COPD patients with severe acute exacerbation

\begin{tabular}{|c|c|c|c|}
\hline \multirow[t]{2}{*}{ Variables } & \multirow{2}{*}{$\frac{\text { Pulmonologist (Group A) }}{\mathrm{N}=29 \text { episodes }}$} & \multirow{2}{*}{$\frac{\text { Internists (Group B) }}{\mathbf{N}=\mathbf{2 9} \text { episodes }}$} & \multirow[t]{2}{*}{$P$-value } \\
\hline & & & \\
\hline The period before admission (days) & $I(I-10)$ & $2(I-7)$ & 0.437 \\
\hline \multicolumn{4}{|l|}{ Cause } \\
\hline Infection & $27(93.2)$ & $16(55.2)$ & 0.001 \\
\hline Poor compliance and inhalation technique & I (3.4) & I (3.4) & - \\
\hline Pollution & I (3.4) & $12(4 \mid .4)$ & 0.001 \\
\hline \multicolumn{4}{|l|}{ Location of admission } \\
\hline Ward & $20(68.9)$ & $23(79.3)$ & 0.539 \\
\hline Intensive care unit & $9(31.1)$ & $6(20.7)$ & 0.368 \\
\hline \multicolumn{4}{|l|}{ Length of stay (days) } \\
\hline Ward & $3.5(I-20)$ & $4.5(2-11)$ & 0.837 \\
\hline Intensive care unit & $3.0(1-7)$ & $5.5(2-29)$ & 0.085 \\
\hline Total & $4.0(1-20)$ & $6(2-29)$ & 0.265 \\
\hline \multicolumn{4}{|l|}{ Cost of treatment $(\$)$} \\
\hline Drug & $213(15-793)$ & $140(\mid 6-1,655)$ & 0.851 \\
\hline Laboratory & $97(3-5 \mid 3)$ & II $4(0-865)$ & 0.561 \\
\hline Chest radiography & $9(0-40)$ & $7(0-25)$ & 0.203 \\
\hline Other & $227(80-1,574)$ & $239(22-4,023)$ & 0.682 \\
\hline Total & $612(159-2,615)$ & $494(578-6,793)$ & 0.657 \\
\hline
\end{tabular}

Notes: Results are expressed as $\mathrm{n}(\%)$ or median (range). Bold values indicate $P$-value reached statistical significance $(<0.05)$.

the health-related quality of life in COPD patients. ${ }^{20} \mathrm{We}$ found a significantly lower referral for pulmonary rehabilitation by internists than pulmonologists; however, both groups were still far from optimal in comparison to guidelines. Patients managed by internists had no referral to pulmonary rehabilitation which has not changed from our previous study conducted several years ago. ${ }^{21}$ Indeed, a systematic review ${ }^{22}$ had also found that referral rates to pulmonary rehabilitation were $3 \%-18 \%$ then, which are in the same range as in our current study. The process of referral even by pulmonologists was often complex and includes barriers such as lack of awareness, engagement at multiple levels, and time consumed as well as perceived difficulty of the referral process. ${ }^{23,24}$ Concerning education, Group A patients received more education on self-management and air pollution avoidance than Group B. The beneficial effect of education on air pollution avoidance might reflect the study result that the possible cause of severe AE from air pollution was significantly less in Group A. These findings on COPD management are in agreement with previous studies showing inconsistency with guidelines for COPD by internists and the benefits of using pulmonologists in the delivery of COPD care. ${ }^{25}$

Significantly lower rates and frequencies of severe $\mathrm{AE}$ were found in Group A, despite the fact that it had higher numbers of disease severity. Although, hospital length of stay and costs of care for severe AE were not significantly different, but those requiring mechanical ventilation in Group B had significantly longer length of stay and higher hospital cost. Our findings contrasted with previous studies where there are no differences in outcome or costs of care for COPD regardless of the source of care, ${ }^{14,15,17}$ and one of the previous studies did not identify any differences in hospital length of stay between patients managed by pulmonologists and internists. ${ }^{14} \mathrm{We}$ also evaluated hospital mortality and readmission with pneumonia, and found no differences in the mortality rates between the two groups. This finding is similar to previous studies. ${ }^{14,15}$ However, this study found statistically significant higher hospital readmission with pneumonia in the group managed

Table 6 Results of treatment for COPD with severe acute exacerbation

\begin{tabular}{llll}
\hline Variables & Pulmonologist (Group A) & Internists (Group B) & P-value \\
\cline { 2 - 3 } & $\mathbf{N}=\mathbf{2 9}$ episodes & $\mathbf{N}=\mathbf{2 9}$ episodes & 0.150 \\
\hline Resolved & $29(100.0)$ & $27(93.1)$ & $2(6.9)$ \\
Dead & 0 & $5(17.2)$ & $\mathbf{0 . 0 1 9}$ \\
Readmission with pneumonia & 0 &
\end{tabular}

Notes: Results are expressed as $n(\%)$. Bold value indicates $P$-value reached statistical significance $(<0.05)$. 
Table 7 Characteristics of COPD with severe acute exacerbation requiring mechanical ventilator

\begin{tabular}{|c|c|c|c|}
\hline \multirow[t]{2}{*}{ Variables } & \multirow{2}{*}{$\begin{array}{l}\text { Pulmonologist (Group A) } \\
\mathrm{N}=10 \text { episodes }\end{array}$} & \multirow{2}{*}{$\begin{array}{l}\text { Internists (Group B) } \\
\mathbf{N}=5 \text { episodes }\end{array}$} & \multirow[t]{2}{*}{$P$-value } \\
\hline & & & \\
\hline Mechanical ventilator (days) & I.5 (I-7) & $5(3-29)$ & 0.005 \\
\hline \multicolumn{4}{|l|}{ Length of stay (days) } \\
\hline Ward & $3(1-14)$ & $5.5(4-1 I)$ & 0.378 \\
\hline Intensive care unit & $2(I-7)$ & $5(2-29)$ & 0.090 \\
\hline Total & $3.5(I-20)$ & $16(6-29)$ & 0.012 \\
\hline \multicolumn{4}{|l|}{ Cost of treatment (\$) } \\
\hline Drug & $277(101-648)$ & $628(140-1,655)$ & 0.070 \\
\hline Laboratory & $\mid 35(|2-44|)$ & $223(140-865)$ & 0.056 \\
\hline Chest radiography & $22(0-28)$ & $51(26-248)$ & 0.022 \\
\hline Other & $134(|34-|, 574)$ & $1,296(259-4,023)$ & 0.055 \\
\hline Total & $863(247-2,496)$ & $2,095(763-6,792)$ & 0.049 \\
\hline
\end{tabular}

Notes: Results are expressed as median (range). Bold values indicate $P$-value reached statistical significance $(<0.05)$.

by internists which is a contradiction to previous studies. ${ }^{14,15}$ There were limitations to this study. Firstly, we did not assess the level of education, health status, or history of AE of the patients in each group that might confound the study results. Secondly, only patients followed up by pulmonologists and internists were studied but not those cared for by other types of generalists, such as family doctors or general practitioners. Thirdly, this study was done in a university hospital, and its results may not be generalizable to other health care institutions. Fourthly, the episodes of severe AE in the study were relatively low, which was probably due to the strict study inclusion criteria defined to enroll only compliant patients with every scheduled visit at least a year prior to enrollment. The small sample size may also affect the statistical result; some differences (eg, mortality, length of stay, cost) are numerically important but not statistically significant.

The results of our study demonstrated that there was an opportunity for cross fertilization of knowledge and practice patterns across clinicians so that all patients could receive evidence-based care in the most efficient manner. Increasing numbers of pulmonologists as the sole care provider for COPD patients is not feasible, especially in developing countries. COPD patients would benefit greatly from a multidisciplinary approach for COPD care delivery, whereas the pulmonologists would complement or reinforce what the internists have managed. In order to study the management of AE patients, strategies should be developed including setting up a prospective multicenter audit.

\section{Conclusion}

There were differences in the management processes of COPD between pulmonologists and internists. In general, management by pulmonologists was in accordance with national COPD guidelines more than by internists, particularly in influenza vaccination, pulmonary rehabilitation, and education. The rates and frequencies of severe AE were significantly lower in patients managed by pulmonologists, and length of hospital stay and cost were significantly lower among the patients with severe AE who required mechanical ventilation. Although there was no statistical difference in hospital mortality due to severe AE, the readmission rate with pneumonia was significantly higher in patients managed by internists.

\section{Acknowledgment}

The authors wish to acknowledge the staff members of the Division of Pulmonary, Critical Care and Allergy, Department of Internal Medicine, Faculty of Medicine, Chiang Mai University, for their contribution to this trial.

\section{Author contributions}

The first author developed the study design and carried out acquisition and interpretation of data, statistical analysis, manuscript preparation, and critical revision of intellectual contents. The other authors contributed to acquisition and interpretation of data, revision of the article for important intellectual contents, and final approval of the version to be published.

\section{Disclosure}

The authors have no conflicts of interest in connection with this work.

\section{References}

1. Rabe KF, Hurd S, Anzueto A, et al; Global Initiative for Chronic Obstructive Lung Disease. Global strategy for the diagnosis, management, and prevention of chronic obstructive pulmonary disease: GOLD executive summary. Am J Respir Crit Care Med. 2007;176(6):532-555. 
2. Wedzicha JA, Seemungal TA. COPD exacerbations: defining their cause and prevention. Lancet. 2007;370:786-796.

3. Donaldson GC, Seemungal TA, Bhowmik A, Wedzicha JA. Relationship between exacerbation frequency and lung function decline in chronic obstructive pulmonary disease. Thorax. 2002;57:847-852.

4. Kanner RE, Anthonisen NR, Connett JE. Lower respiratory illnesses promote $\mathrm{FEV}_{1}$ decline in current smokers but not ex-smokers with mild chronic obstructive pulmonary disease: results from the lung health study. Am J Respir Crit Care Med. 2001;164:358-364.

5. Seemungal TA, Donaldson GC, Paul EA, Bestall JC, Jeffries DJ, Wedzicha JA. Effect of exacerbation on quality of life in patients with chronic obstructive pulmonary disease. Am J Respir Crit Care Med. 1998; 157:1418-1422.

6. Miravitlles M, Ferrer M, Pont A, et al; IMPAC Study Group. Effect of exacerbations on quality of life in patients with chronic obstructive pulmonary disease: a 2 year follow up study. Thorax. 2004;59:387-395.

7. Soler-Cataluna JJ, Martinez-Garcia MA, Roman SP, Salcedo E, Navarro M, Ochando R. Severe acute exacerbations and mortality in patients with chronic obstructive pulmonary disease. Thorax. 2005;60:925-931.

8. Connors AF Jr, Dawson NV, Thomas C, et al. Outcomes following acute exacerbation of severe chronic obstructive lung disease. The SUPPORT investigators (study to understand prognoses and preferences for outcomes and risks of treatments). Am J Respir Crit Care Med. 1996;154:959-967.

9. Sullivan SD, Ramsey SD, Lee TA. The economic burden of COPD. Chest. 2000;117:5S-9S.

10. Britton M. The burden of COPD in the U.K.: results from the Confronting COPD survey. Respir Med. 2003;97(suppl C):S71-S79.

11. GOLD. The Global Strategy for the Diagnosis, Management and Prevention of COPD, Global Initiative for Chronic Obstructive Lung Disease (GOLD); 2008. Available from: http://www.goldcopd.org/. Accessed July 4, 2014.

12. Chen J, Radford MJ, Wang Y, Krumholz HM. Care and outcomes of elderly patients with acute myocardial infarction by physicians specialty: the effects of comorbidity and functional limitations. $\mathrm{Am}$ J Med. 2000;108:460-469.

13. Diette G, Skinner EA, Nguyen TT, Markson L, Clark BD, Wu AW. Comparison of quality of care by specialist and generalist physicians as usual source of asthma care for children. Pediatrics. 2001;108:432-437.

14. Diaz-Fuentes G, Lakshmi V, Blum S, Sy S, Escalera E. Chronic obstructive pulmonary disease: comparison of care by specialists and generalists in an inner-city hospital. Int J Pul Med. 2004;5(1). Available from: https://ispub.com/IJPM/5/1/12172. Accessed July 4, 2014.
15. Strauss MJ, Conrad D, LoGerfo JP, Hudson LD, Bergner M. Cost and outcome of care for patients with chronic obstructive lung disease: analysis by physician specialty. Med Care. 1986;24(10):915-924.

16. Wijayaratne K, Wilson J, Sivakumaran P, Sriram KB. Differences in care between general medicine and respiratory specialists in the management of patients hospitalized for acute exacerbations of chronic obstructive pulmonary disease. Ann Thorac Med. 2013;8(4):197-203.

17. Angus RM, Murray S, Kay JW, Thomson NC, Patel KR. Management of chronic airflow obstruction: differences in practice between respiratory and general physicians. Respir Med. 1994;88:493-497.

18. Miller MR, Hankinson J, Brusasco V, et al. ATS/ERS task force: standardization of lung function test. Eur Respir J. 2005;26:319-338.

19. Pothirat C, Chaiwong W, Phetsuk N, et al. Long-term efficacy of intensive cycle ergometer exercise training program for advanced COPD patients. Int J Chron Obstruct Pulmon Dis. 2015;10(1):133-144.

20. Puhan MA, Gimeno-Santos E, Scharplatz M, Troosters T, Walters EH, Steurer J. Pulmonary rehabilitation following exacerbations of chronic obstructive pulmonary disease. Cochrane Database Syst Rev. 2011;5:CD005305.

21. Pothirat C, Phetsuk N, Deesomchok A, et al. Clinical characteristics, management in real world practice and long-term survival among COPD patients of Northern Thailand COPD club members. J Med Assoc Thai. 2007:90:653-662.

22. Lodewijckx C, Sermeus W, Vanhaecht K, et al. In hospital management of COPD exacerbations: a systematic review of the literature with regard to adherence to international guidelines. $J$ Eval Clin Pract. 2009;15:1101-1110.

23. Johnston K, Grimmer-Somers K, Young M, Antic R, Frith P. Which chronic obstructive pulmonary disease care recommendations have low implementation and why? A pilot study. BMC Res Notes. 2012; 5:652.

24. Harris D, Hayter M, Allender S. Factors affecting the offer of pulmonary rehabilitation to patients with chronic obstructive pulmonary disease by primary care professionals: a qualitative study. Prim Health Care Res Dev. 2008;9:280-290.

25. Decramer M, Bartsch P, Pauwels R, Yernault JC. Management of COPD according to guidelines. A national survey among Belgian physicians. Monaldi Arch Chest Dis. 2003;59(1):62-80.
International Journal of COPD

\section{Publish your work in this journal}

The International Journal of COPD is an international, peer-reviewed journal of therapeutics and pharmacology focusing on concise rapid reporting of clinical studies and reviews in COPD. Special focus is given to the pathophysiological processes underlying the disease, intervention programs, patient focused education, and self management protocols.

\section{Dovepress}

This journal is indexed on PubMed Central, MedLine and CAS. The manuscript management system is completely online and includes a very quick and fair peer-review system, which is all easy to use. Visit http://www.dovepress.com/testimonials.php to read real quotes from published authors. 